\title{
The levonorgestrel-releasing intrauterine system: Safety, efficacy, and patient acceptability
}

This article was published in the following Dove Press journal:

Therapeutics and Clinical Risk Management

21 July 2009

Number of times this article has been viewed

\author{
Megan N Beatty \\ Paul D Blumenthal \\ Department of Obstetrics and \\ Gynecology, Stanford University, \\ Stanford, CA, USA
}

Correspondence: Paul D Blumenthal Department of Obstetrics and Gynecology, 300 Pasteur Drive, Stanford University Hospital, C/O Office of Obstetrics and Gynecology, Stanford, CA 94305, USA

Email pblumen@stanford.edu

\begin{abstract}
The levonorgestrel-releasing intrauterine system (LNG-IUS) is a safe, effective and acceptable form of contraception used by over 150 million women worldwide. It also has a variety of noncontraceptive benefits including treatment for menorrhagia, endometriosis, and endometrial hyperplasia. The LNG-IUS has also been used in combination with estrogen for hormone replacement therapy and as an alternative to hysterectomy. Overall, the system is very well tolerated and patient satisfaction is quite high when proper education regarding possible side effects is provided. However, despite all of the obvious benefits of the LNG-IUS, utilization rates remain quite low in the developed countries, especially in the United States. This is thought to be largely secondary to the persistent negative impressions from the Dalkon Shield intrauterine experience in the 1970s. This history continues to negatively influence the opinions of both patients and health care providers with regards to intrauterine devices. Providers should resolve to educate themselves and their patients on the current indications and uses for this device, as it, and intrauterine contraception in general, remains a largely underutilized approach to a variety of women's health issues.
\end{abstract}

Keywords: Mirena ${ }^{\circledR}$, levonorgestrel-releasing, intrauterine system, intrauterine contraceptive device

\section{Introduction}

Worldwide, intrauterine devices (IUDs) are the most widely used and effective reversible contraceptive method and are safe, extremely "low maintenance" contraceptives. They are second only to female sterilization as the most prevalent method of family planning worldwide (13.6\% vs 20.5\%). ${ }^{1}$ Over 150 million women worldwide use the IUD for contraception. However, for a variety of reasons, including the continued concern many women have about the morbidity and mortality associated with IUDs resulting (whether they know it or not) from the Dalkon shield experience of the 1970s, there is a large disparity between the numbers of users in developing versus developed countries. There is an especially low utilization rate within the United States. Nearly $15 \%$ of women who use contraception in less developed countries choose the IUD, compared with only $8 \%$ of women in developed countries and only $2 \%$ in the United States. Two thirds of worldwide IUD use (over 100 million women) is represented by China alone. ${ }^{2}$

There is currently a wide variety of IUDs available worldwide; some are inert, some are copper containing, and some are medicated with levonorgestrel or indomethacin. They also come in a wide variety of sizes and shapes including T-shaped and "frameless" devices. This article will focus specifically on the LNG-IUS, exploring

submit your manuscript | www.dovepress.con 
mechanism of action, safety, efficacy, variety of uses, and patient acceptability.

\section{Mechanism of action of the levonorgestrel-releasing intrauterine system}

The levonorgestrel-releasing intrauterine system (LNGIUS) has been available in Europe since 1990 and the United States since 2000. It is marketed under the name Mirena $^{\circledR}$ (Bayer Schering Pharma, Berlin, Germany). The LNG-IUS provides highly effective contraception for up to five years, with potential for approval for up to seven years in the near future. The mechanisms of action of the LNG-IUS are similar to that of levonorgestrel implants or levonorgestrel-containing mini-pills, although it accomplishes these effects with much lower peak serum levels than other progestin-containing contraceptives $(0.1-0.4 \mathrm{ng} / \mathrm{ml}$ vs $1.7-15.2 \mathrm{ng} / \mathrm{ml}$ with combined and progestin-only oral contraceptives, respectively, and $5.4 \mathrm{ng} / \mathrm{ml}$ for combined vaginal preparations). ${ }^{1}$ The LNG-IUS is a T-shaped device composed of a cylinder containing $52 \mathrm{mg}$ of LNG covered by a rate-controlling membrane which serves to regulate the rate of hormonal release (Figure 1). ${ }^{3}$ Initially, $20 \mu \mathrm{g}$ of levonorgestrel is released every 24 hours from this polymer cylinder. This decreases to $11 \mu \mathrm{g}$ every 24 hours by the end of five years, with an average release rate of $14 \mu \mathrm{g}$ per day over the life of the IUS. Levonorgestrel, a highly potent second generation progestin, thickens cervical mucus and suppresses

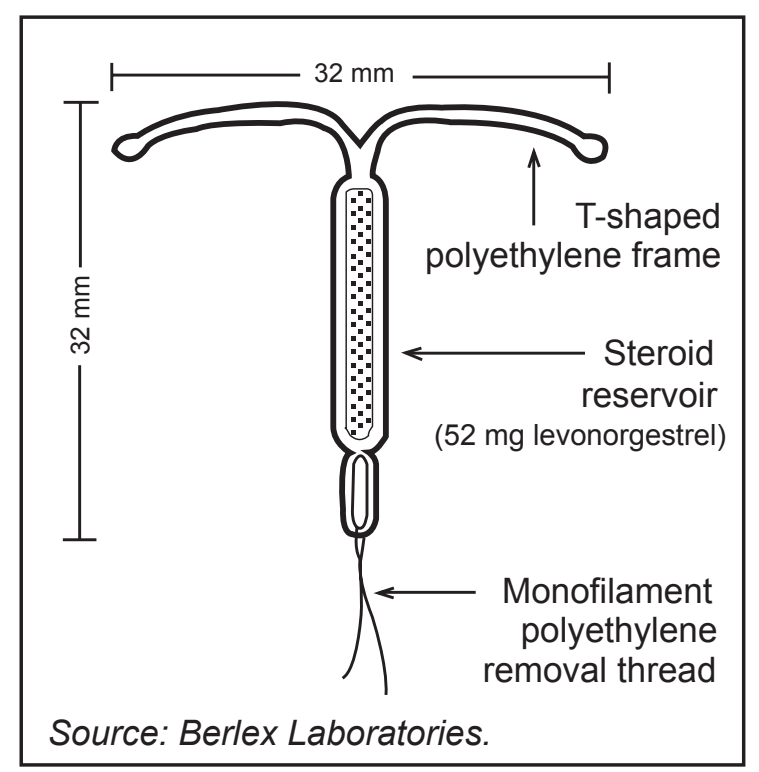

Figure I Levonorgestrel-releasing intrauterine system (LNG-IUS, Mirena $\left.{ }^{\circledR}\right)^{3}$ endometrial proliferation (preventing decidualization of the stroma). This creates a hostile environment for sperm survival, inhibiting motility and capacitation with the net effect combining to prevent fertilization. ${ }^{1}$

The LNG-IUS also produces endometrial thinning with fragile superficial vessels which, in the unlikely event of fertilization, may prevent implantation. The low serum levels of absorbed progestin are below the threshold for inhibition of ovulation, so that most women with the LNG-IUS continue to ovulate regularly. ${ }^{1}$

As a result of these various contraceptive actions, the efficacy rate of the LNG-IUS is high, with only $0.1 \%$ of women experiencing an unintended pregnancy within the first year of typical use. In four clinical studies, representing more than 10,000 woman-years of use, the average Pearl Index (a statistical estimation of the number of unintended pregnancies in 100 woman-years of exposure to a contraceptive method) was $0.1 .^{4}$

\section{Candidates and contraindications for intrauterine contraception and the LNG-IUS}

\section{Candidates and contraindications}

\section{for intrauterine devices in general}

Intrauterine contraceptive devices are appropriate contraceptive options for women who desire a very convenient, long-term contraceptive or who are considering sterilization. While there are contraindications to utilization of an IUD, they are relatively few compared to some other methods. Some contraindications, for example pregnancy, are absolute and undisputed. However, other contraindications, such as patients at increased risk of sexually transmitted infections or nulliparous women, are more controversial. The recommendations regarding these issues vary based on which specific organization is consulted (Table 1).

One of the most contentious contraindications to IUD use relates to patients who are perceived to be at increased risk for sexually transmitted infections (STIs). This concern likely dates back to the experience with the Dalkon Shield in the 1970s. The Dalkon Shield IUD was associated with an unacceptably high risk of pelvic inflammatory disease, tubal infertility and septic abortion, to a significant extent secondary to its braided polyfilament tail..$^{5}$ It was subsequently removed from the market, and is thought by many to be responsible for the initial significant decline and continued slow increase in numbers of patients interested in using IUDs for contraception. After the 
Table I Contraindications to the levonorgestrel-releasing intrauterine system according to organizational recommendations

\begin{tabular}{|c|c|c|c|}
\hline Condition & $\mathrm{ACOG}^{55}$ & $\begin{array}{l}\text { WHO }{ }^{13,16} \\
\text { (for the definition of risk } \\
\text { categories see Appendix B) }\end{array}$ & Manufacturer $^{3}$ \\
\hline $\begin{array}{l}\text { Uterine anomaly } \\
\text { (including fibroids causing } \\
\text { distortion of the uterine } \\
\text { cavity) }\end{array}$ & Contraindicated & Risk category 4 & Contraindicated \\
\hline $\begin{array}{l}\text { History of pelvic } \\
\text { inflammatory disease }\end{array}$ & $\begin{array}{l}\text { Contraindicated } \\
\text { (past three months only) }\end{array}$ & No contraindication & $\begin{array}{l}\text { Contraindicated } \\
\text { (if no subsequent } \\
\text { pregnancy) }\end{array}$ \\
\hline $\begin{array}{l}\text { Post-partum endometritis } \\
\text { or septic abortion in the } \\
\text { last three months }\end{array}$ & Contraindicated & $\begin{array}{l}\text { Immediate insertion only, risk } \\
\text { category not defined }\end{array}$ & Contraindicated \\
\hline Active cervicitis/vaginitis & Contraindicated & $\begin{array}{l}\text { Initiation of LNG-IUS is risk } \\
\text { category } 4 \text {, continuation is risk } \\
\text { category } 2 \text { for cervicitis; both } \\
\text { are risk category } 2 \text { for vaginitis }\end{array}$ & Contraindicated \\
\hline $\begin{array}{l}\text { Immunosuppression } \\
\text { (eg, leukemia, AIDS, } \\
\text { intravenous drug abuse) }\end{array}$ & No recommendation & $\begin{array}{l}\text { Initiation is risk category } 3 \text {, } \\
\text { continuation category } 2 \text {. } \\
\text { If AIDS patient is clinically } \\
\text { well on antiretroviral therapy, } \\
\text { initiation is also category } 2 \text {. } \\
\text { Not contraindicated in HIV. }\end{array}$ & Contraindicated \\
\hline $\begin{array}{l}\text { Known or suspected } \\
\text { cervical dysplasia/genital } \\
\text { bleeding of unknown } \\
\text { etiology }\end{array}$ & Contraindicated & $\begin{array}{l}\text { Initiation is risk category } 4, \\
\text { continuation is risk category } 2\end{array}$ & Contraindicated \\
\hline $\begin{array}{l}\text { Known or suspected } \\
\text { breast carcinoma }\end{array}$ & Contraindicated & $\begin{array}{l}\text { Risk category } 4 \text { for current, } \\
\text { category } 2 \text { for past with no } \\
\text { evidence of disease for the last } \\
\text { five years }\end{array}$ & Contraindicated \\
\hline Pregnancy & Contraindicated & Risk category 4 & Contraindicated \\
\hline $\begin{array}{l}\text { Post-partum }<48 \text { hours } \\
\text { (including insertion } \\
\text { immediately after } \\
\text { delivery of the placenta) }\end{array}$ & No recommendation & $\begin{array}{l}\text { Risk category I if not breast } \\
\text { feeding, category } 3 \text { if breast } \\
\text { feeding }\end{array}$ & No recommendation \\
\hline $\begin{array}{l}\text { Post-partum } \geq 48 \text { hours } \\
\text { to }<4 \text { weeks }\end{array}$ & No recommendation & Risk category 3 & No recommendation \\
\hline $\begin{array}{l}\text { Active viral hepatitis, } \\
\text { liver tumor (benign or } \\
\text { malignant), cirrhosis }\end{array}$ & $\begin{array}{l}\text { Not recommended for } \\
\text { "current liver disease" }\end{array}$ & $\begin{array}{l}\text { Risk category } 3 \text { for } \\
\text { malignant hepatoma, benign } \\
\text { hepatocellular adenoma, or } \\
\text { decompensated cirrhosis, } \\
\text { category } 2 \text { for focal nodular } \\
\text { hyperplasia }\end{array}$ & Contraindicated \\
\hline $\begin{array}{l}\text { History of, or condition } \\
\text { that predisposes to, } \\
\text { ectopic pregnancy }\end{array}$ & No contraindication & No contraindication & $\begin{array}{l}\text { Recommends } \\
\text { caution }\end{array}$ \\
\hline Current DVT/PE & No recommendation & $\begin{array}{l}\text { Risk category } 3 \text {, category } 2 \text { if } \\
\text { established on anticoagulant } \\
\text { therapy }\end{array}$ & No recommendation \\
\hline
\end{tabular}

Abbreviations: ACOG, American College of Obstetricians and Gynecologists; AIDS, acquired immunodeficiency syndrome; DVT, deep vein thrombosis; HIV, human immunodeficiency virus; PE, pulmonary embolism; WHO, World Health Organization.

dismal experience with the Dalkon Shield physicians understandably were, and despite current reassuring data often continue to be, hesitant to prescribe this for unmarried women or patients with multiple sexual partners because of the persistent concern over serious pelvic infections and implications for future fertility. However, numerous studies on the currently available versions of the IUD have shown that, overall, IUD users are no more 
likely to suffer from PID than control women. One model estimated that the risk of clinical PID secondary to IUD use is only $0.15 \% .{ }^{6}$ Another recent study evaluating a high-risk population in West Africa showed the risk of PID related to IUD insertion to be only $0.075 \% .^{7}$ One randomized trial (with data collection in the early 1980s) showed a decreased rate of PID among LNG-IUS users compared to users of a copper-containing IUD. ${ }^{8}$ The IUD may, therefore, be a reasonable option for women who may be at risk for sexually transmitted infections. This is especially the case where prevalence in the community as a whole may be high but individual risk may be low (ie, no current or recent history of an STI or the patient uses condoms regularly if she has more than one partner). Morrison and colleagues developed a checklist to help with risk assessment for STIs in candidates for IUD insertion which may be helpful with management decisions (Appendix A). ${ }^{9}$ Of note, all women must still be counseled on safe sex practices, and condom use must be encouraged.

The appropriateness of IUD use in nulliparous women has also been controversial because of a variety of concerns specific to this group. First, because of the smaller size of the uterus it was thought that there might be an increased expulsion rate. In addition, because of the more stenotic nulliparous os, the device may cause increased pain with insertion. There has also been concern over a possible increased rate of infertility in these women, again secondary to the concern over increased rates of PID with the IUD and the thought that nulliparous women are less likely to be in stable, monogamous relationships. However, these concerns are not supported by recent studies. A retrospective cohort study of 129 nulliparous and 332 parous women showed that rates of expulsion for the levonorgestrel-releasing IUDs were $0 \%$ to $0.2 \%$ per year, and that nulliparous women did not show more complications than parous women. ${ }^{10}$ A comparative cross-sectional study of 227 nulliparous women and 2,080 parous women showed similar reasons for removal between the two groups: $49.1 \%$ vs $48.2 \%$ because of device expiration, $21.7 \%$ vs $15.4 \%$ desired planned pregnancy, $4.8 \%$ vs $6.3 \%$ were secondary to accidental pregnancy, $1.6 \%$ vs $1.1 \%$ because of PID. There were actually decreased rates of expulsion in the nulliparous group (1.6\% vs 5.1\%), and slightly increased rates of pain/bleeding (14.5\% vs $10.2 \%) .{ }^{11}$ According to the medical eligibility criteria for contraceptive use developed by the World Health Organization (WHO), nulliparity is a condition for which the advantages of using intrauterine contraception generally outweigh the theoretical or proven risks (risk category 2. For the full definition of WHO risk categories please see Appendix B). ${ }^{12}$ The intrauterine device is, therefore, generally considered to be a safe and effective contraceptive which should be offered to nulliparous women as part of their family planning counseling.

There are no WHO restrictions for using IUDs among women who have uncomplicated valvular disease. When valvular heart disease is complicated by pulmonary hypertension, atrial fibrillation, or subacute bacterial endocarditis, prophylactic antibiotics should be administered to women with these conditions before an IUD is inserted to prevent endocarditis.

\section{Candidates and contraindications for the LNG-IUS}

The WHO provides highly useful guidelines regarding the appropriateness of the LNG-IUS for women with a variety of medical conditions (see Appendix B for the definition of WHO risk categories for eligibility for use of an intrauterine device). According to the WHO, women who have any degree of hypertension can use a LNG-IUS if no other risk factors for cardiovascular disease are present. When multiple risk factors do exist, the risk of cardiovascular disease may increase substantially. For this reason, because progestins have been shown in clinical trials to influence lipid metabolism, ${ }^{13}$ there has been concern, albeit theoretical, about the effect of levonorgestrel-releasing IUDs on lipid levels in women with a history of heart disease or stroke. ${ }^{12}$ However, these concerns about the effect of the LNG-IUS on lipid profiles have not been borne out. A recent study of 48 patients who had the LNG-IUS inserted for menorrhagia showed no significant change from baseline in mean total cholesterol, triglycerides, low-density lipoprotein (LDL) or very low density lipoprotein (VLDL) at the end of one year. ${ }^{14}$ Another study of 92 women with the LNG-IUS inserted for menorrhagia showed a marginally significant reduction in total cholesterol from baseline, a reduction in HDL at 6 months which reverted to baseline by one year, while triglycerides, LDL, apolipoprotien A1 and apolipoprotein B remained stable over the course of 18 months. ${ }^{15}$ Therefore, though the WHO recommendations warn of a theoretical effect of the LNG-IUS on lipid levels and caution its use in women with multiple cardiac risk factors, studies do not show this to be a significant problem associated with the LNG-IUS.

Progestins are thought to increase the risk for deep vein thromboses (DVTs) and pulmonary emboli, although this increase is substantially less with a levonorgestrel-releasing IUS than with combined oral contraceptives. Since risks associated with the LNG-IUS are even greater for women 
who have a current DVT, the WHO states that the risks of using the LNG-IUS in such a situation usually outweigh the benefits (risk category 3 ) until they are established on anticoagulant therapy (risk category 2). ${ }^{12,16}$

Among women who are infected with the human immunodeficiency virus (HIV) or are at risk of becoming infected with this pathogen, there is no known interaction between antiretroviral therapy and LNG-IUS use. The WHO, however, classifies insertion of a LNG-IUS in a woman with acquired immunodeficiency syndrome (AIDS) as a category 3 risk and continuation of the IUD as a category 2 risk unless the patient is clinically well and on antiretroviral therapy. In this case, insertion of an IUS is then considered to provide benefits that generally outweigh any theoretical or proven risk. Although IUD use is not associated with an increased risk of HIV transmission to sexual partners, these women should be counseled about safe sex practices and condom use must be encouraged. ${ }^{12}$

\section{Insertion of the LNG-IUS}

Although the intrauterine contraceptive device should ideally be inserted within the first seven days following a woman's menstrual cycle, it can be inserted at any time during the cycle if it is reasonably certain that she is not pregnant and has not been at risk of pregnancy during that cycle. As discussed in more detail later (please see "Efficacy of the LNG-IUS"), an IUD may be safely inserted immediately after uncomplicated spontaneous or induced abortions, including those that are performed during the second trimester. Expulsion, pregnancy, and removal rates after first-trimester termination are comparable to those found in studies in which the device was inserted during or immediately after menses. The shorter the period of gestation at the time of spontaneous or induced abortion, the lower the event rates following IUD insertion. The LNG-IUS can also be safely inserted immediately after childbirth, but there are associated risks with insertion during the immediate postpartum period. If an IUD is inserted within the first 48 hours after childbirth, the risk of expulsion is greater than interval insertion, although the risk of expulsion is somewhat lower if the IUD is inserted within 10 minutes of the delivery of the placenta. If an IUD is inserted 48 hours and up to four weeks after childbirth, the risk of perforation is greater. According to the WHO medical eligibility criteria for contraceptive use, there are no restrictions for inserting an IUD four or more weeks after childbirth; however, no distinction is made between a vaginal or caesarean delivery. The type of delivery is important, because a cesarean section can distort the uterine anatomy. If the distortion is found to be significant during a bimanual examination, then inserting the IUD may be aided by uterine ultrasonography. ${ }^{17}$

Adhering to the proper insertion method and using a sterile or "no-touch" technique are sufficient to decrease the risk of infection, uterine perforation, and expulsion. Data indicate that antibiotic prophylaxis does not prevent the rare occurrence of infections acquired at the time of insertion. A Cochrane review performed to assess the effectiveness of prophylactic antibiotic administration before IUD insertion in reducing IUD-related complications and discontinuations within three months of insertion showed little benefit from prophylactic antibiotics on early removal or occurrence of PID following insertion. ${ }^{18}$ Prophylactic antibiotics are therefore not recommended prior to insertion of the IUD.

Pain may occur during the insertion procedure that may result from a vasovagal reaction, the need for cervical dilation, difficulty with insertion, and uterine perforation. While some clinicians administer ibuprofen or another nonsteroidal anti-inflammatory drug (NSAID) to control such pain, a recent study of 2,019 first-time IUD users found that ibuprofen had no significant impact on reducing pain. ${ }^{19}$ In a comparative study conducted in the United Kingdom, 102 women presenting for IUD insertion were randomly assigned to 1 of 3 groups: no pretreatment, pretreatment with $2 \%$ lignocaine gel (Instillagel) applied to the cervical canal, and pretreatment with an inert gel. Pain scores for women in the nontreatment groups were significantly higher $(\mathrm{p}<0.025)$ than those in the lignocaine group. These results suggest that a local lignocaine gel has the potential for reducing the pain and discomfort experienced during IUD insertion. ${ }^{20}$ In an attempt to reduce cervical resistance, a randomized, controlled trial was undertaken among 80 nulliparous women randomly assigned to receive sublingually $400 \mu \mathrm{g}$ misoprostol and $100 \mathrm{mg}$ diclofenac or $100 \mathrm{mg}$ diclofenac alone one hour prior to IUD insertion. Following treatment with misoprostol, insertion was significantly easier with fewer difficult and failed attempts at insertions than in the control group. However, pain scores, estimated using a visual analogue scale (VAS; $1-10$ ), were not different between the groups. ${ }^{21}$ Therefore, there may be some benefit to use of misoprostol for cervical ripening prior to LNG-IUS insertion as well as local anesthetic use for pain control, while NSAIDs appear to be of little benefit.

\section{Efficacy of the levonorgestrel- releasing IUS}

The IUD, in general, is one of the most effective forms of contraception available today, with a global cumulative 
pregnancy rate of $<2 \%$ at five years. The LNG-IUS, in particular, is possibly the most effective IUD available according to numerous studies that show its global cumulative pregnancy rate to be $<0.5 \%{ }^{22} \mathrm{~A}$ large randomized-controlled trial of 2,244 women over seven years showed a pregnancy rate of $1.1 \%$ with the LNG-IUS compared with $1.4 \%$ with the TCu380. ${ }^{23}$ In two other seven-year follow up studies with 293 and 82 women respectively, there were no pregnancies in women using the LNG-IUS. ${ }^{24,25}$ A Cochrane review in 2004 showed the LNG-IUS to be as effective as copper IUDs with a copper surface area of $>250 \mathrm{~mm}^{2}$, and more effective than those with $<250 \mathrm{~mm}^{22,26}$

The LNG-IUS is also an effective option for women to choose immediately post abortion. Multiple studies have shown that copper-releasing IUDs are safe and effective during this timeframe. Fewer studies have been done looking specifically at the LNG-IUS under this circumstance; however, they have shown it to be at least as effective as the copper IUD. One study followed 305 women who received the Mirena ${ }^{\circledR}$ IUS immediately post-abortion for up to five years. There were a total of two pregnancies for a pregnancy rate of $0.8 \%$ at five years. There was a discontinuation rate secondary to expulsion of $7.1 \%$ at one year and $10.5 \%$ at five years ${ }^{27}$ which is obviously higher than the interval expulsion rate of $2 \%-3 \%$ per year, ${ }^{28}$ but not significantly different than that of the NovaT $(8.6 \%$ at one year and $15.4 \%$ at five years). ${ }^{28}$ A LNG-IUS may, therefore, be safely inserted immediately after either uncomplicated spontaneous or induced abortions.

The levonorgestrel-releasing intrauterine system can also be safely inserted immediately after childbirth, but there is also an increased risk of expulsion compared with interval insertion. A study of 19 women who received a post placental LNG-IUS, defined as placement within 10 minutes of placental delivery, showed an expulsion rate of $10.5 \%$ and no infections. ${ }^{27}$ There are no studies that specifically examine the timing of LNG-IUS insertion post partum, but one done with a copper-releasing IUD showed post-placental IUD insertion to have significantly lower expulsion rate $(14.3 \%$ complete and $22.6 \%$ partial) than early post partum insertion, defined as taking place $10 \mathrm{~min}$ to 72 hours after delivery of the placenta, at the end of one year $(18.6 \%$ complete and $51.2 \%$ partial). Both rates were much higher than interval insertion (3.8\% complete and 3.1\% partial). There were no perforations in either of the post partum groups, and $2.3 \%$ perforation rate in the interval groups. ${ }^{29}$ Insertion of the LNGIUS is therefore a reasonable, almost effortless, option for post placental insertion if the woman is properly counseled about the increased risk of expulsion versus interval insertion and receives proper counseling on checking the IUS strings and receives appropriate clinical follow-up. For many lowresource settings, since the cervix (or uterus in the case of insertions at Cesarean delivery) is open at delivery and the patient is commonly in lithotomy position, post-placental insertion may reduce the barriers to interval insertions such as lack of speculae, tenacula, sounds, exam tables, and already crowded clinics.

\section{Noncontraceptive benefits of LNG-IUS}

Like oral contraceptives, the levonorgestrel-releasing intrauterine system confers important noncontraceptive health benefits. The Mirena ${ }^{\circledR}$ LNG-IUS can be effective in treating a variety of gynecological disorders including menorrhagia, dysmenorrhea, pain associated with endometriosis, anemia, endometrial hyperplasia and can be used as an alternative to hysterectomy for women with bleeding problems as well as an adjunct to estrogen replacement therapy.

\section{The LNG-IUS as treatment for menorrhagia}

Menorrhagia, defined as $>80 \mathrm{~mL}$ of menstrual blood loss, is a common health problem affecting up to 2.5 million women in the United States annually. It accounts for a loss of $8 \%$ of employee wages in the USA, and is a major reason for women to present to their health care provider for invasive procedures, including hysterectomy..$^{30}$ The prevalence of menorrhagia increases with increasing age, peaking in the perimenopausal period. Nearly half a million women annually in the United States alone undergo hysterectomy because of bleeding disorders, with the associated health care costs, time from work, and morbidity that accompany this operative treatment. ${ }^{30}$ There are a variety of medical and surgical treatments available for menorrhagia, including prostaglandin synthetase inhibitors, antifibrinolytic agents, oral contraceptive pills, and endometrial ablation. However, most of these treatments have only been shown to improve menstrual bleeding by $20 \%-50 \%{ }^{30}$ In addition, the associated side effects and repetitive nature of these treatments significantly impairs patient compliance. In contrast, the LNG-IUS has been used in numerous studies as a treatment of menorrhagia, with a reduction in menstrual blood flow of $86 \%-97 \% .^{30}$ One study comparing the LNG-IUS and norethisterone showed that the LNG-IUS reduced menstrual blood flow by $94 \%$, with norethisterone by a close $87 \%$. However, after three cycles of treatment, $76 \%$ of the 
LNG-IUS group wished to continue the treatment, compared with only $22 \%$ of the medical therapy group. ${ }^{31}$

In addition, the LNG-IUS has been used in numerous studies to compare outcomes with hysterectomy for treatment of menorrhagia. A randomized controlled trial of 236 women assigned either to LNG-IUS or hysterectomy showed that after one year the two treatments were associated with equal improvements in health status, quality of life, and psychosocial well-being, but the IUS was more costeffective. Of note, $20 \%$ of the women in the LNG-IUS group did go on to receive hysterectomies because of continued bleeding. ${ }^{32}$ Another study which looked specifically at the cost-effectiveness of oral contraceptives versus LNG-IUS versus surgical management (including both ablation and hysterectomy) for dysfunctional uterine bleeding (DUB) showed the LNG-IUS to be the most cost-effective of all three treatments. ${ }^{33}$ A Cochrane review of the subject concluded that use of the LNG-IUS results in a significant decrease from baseline in the amount of menstrual bleeding, and that it is more cost-effective as a treatment for menorrhagia than hysterectomy both at one and five years. ${ }^{34}$ The LNG-IUS is, therefore, a satisfactory, effective, and economical alternative to medical and surgical treatment of menorrhagia.

\section{The LNG-IUS as treatment for endometriosis}

Endometriosis is a significant problem affecting 5\%-10\% of reproductive age women in the United States. ${ }^{35}$ It is associated with chronic pelvic pain, dyspareunia and infertility, and is often a significant detriment to a patient's quality of life. Treatment has historically consisted of some combination of nonsteroidal anti-inflammatory medications (NSAIDs), progestational medications such as depot medroxyprogesterone acetate (DMPA) that function as anti-estrogens, ovulation suppression with oral contraceptive pills, androgenic medications such as danazol, gonadotropin-releasing hormone ( $\mathrm{GnRH}$ ) analogues to induce temporary pseudo-menopause, and surgical ablation. However, the hypoestrogenic side effects associated with many of these medical treatments and the invasive nature of the surgical treatment are a limiting factor to both the clinical ability to continue the treatment long term and patient compliance. The LNG-IUS has recently been studied as an alternative for treating the pain and symptoms associated with endometriosis, as it addresses both the patient compliance and the long-term use issues. A randomized-controlled clinical trial of 82 women with chronic pelvic pain from endometriosis compared 39 women treated with the LNG-IUS with 43 women treated with a
GnRH analogue. After six months, both groups showed significant improvement in pain scores throughout the six months of treatment, with those women with stage III or IV endometriosis receiving the fastest improvement. There was no difference in quality of life reported, and the LNG-IUS group had the benefits of fewer hypoestrogenic side effects, and only requiring one intervention every five years. ${ }^{36}$ After 36 months, $59 \%(n=23)$ of the women in the LNG-IUS group were still using the device. The VAS pain score in this group was $0-3$ (indicating excellent pain control) in $82.6 \%$, and $\geq 7$ in only $8.6 \%$. In the former users of the GnRH analogue, $28 \%$ were using some form of hormonal contraceptives to control pain, and $47.5 \%$ continued to have excellent pain control, while only $2.5 \%$ had a pain score $\geq 7$. Therefore, while both treatments are effective in pain control for up to 3 years, the LNG-IUS may be the treatment of choice for women who do not wish to become pregnant because it can provide both effective pain control and contraceptive protection. ${ }^{37}$

Another study of 34 women with surgically staged minimal to moderate endometriosis who were treated with the LNG-IUS for up to 36 months showed a decrease in the visual analog pain scale (VAS) from an initial score of 7.7/10 to 2.7 at 36 months. There was also a decrease in the verbal rating scale (VRS) of both dysmenorrhea and noncyclic pelvic pain from an initial $25 / 96$ to 8.4 after 36 months as well as a decrease in total days of pain per 28-day period from 15.0 to 6.0 after 12 months. ${ }^{38}$

A randomized-controlled clinical trial of 40 women who underwent conservative surgical treatment for moderate to severe endometriosis compared 20 women who received a postoperative LNG-IUS with 20 women who were managed expectantly postoperatively. The study showed that $10 \%$ of the women who received the LNG-IUS had a recurrence of moderate to severe endometriosis after 12 months, compared with $45 \%$ of the expectantly managed group. There was also an absolute risk reduction in recurrence of dysmenorrhea in the LNG-IUS group of $35 \%$, as well as a decrease in recurrence rates of dyspareunia. ${ }^{39}$ The LNG-IUS appears to be an effective treatment for the pain symptoms associated with endometriosis, and is associated with fewer intervention requirements, fewer hypoestrogenic side effects, and increased patient satisfaction rates than many of the other alternative treatments clinically available.

\section{The LNG-IUS as treatment for adenomyosis}

Adenomyosis is a relatively common disorder affecting women, usually in their $40 \mathrm{~s}$ and 50 s, characterized by the 
presence of heterotopic endometrial glands and stroma in the myometrium with hyperplasia of the adjacent smooth muscle. The symptoms include menorrhagia (40\%-50\%), dysmenorrhea (15\%-30\%), and metrorrhagia (10\%-12\%). ${ }^{40}$ Historically, diagnosis and definitive treatment for adenomyosis has been hysterectomy. However, diagnosis has recently become possible using a combination of transvaginal ultrasound and magnetic resonance imaging. As a result, there has been a concerted effort on the part of gynecologists to find an effective, but less invasive treatment for the disorder. The options for this condition include endometrial ablation, danazol and GnRH agonists. However, endometrial ablation is not effective for this condition as it does not penetrate deeply enough into the myometrium. In addition, as discussed previously with regards to treatment for endometriosis, in light of the side effects of the other forms of medical treatment listed, the LNG-IUS is becoming an increasingly attractive option for treatment of adenomyosis. It is hypothesized to work on adenomyosis in two ways. First, as discussed earlier, it causes decidualization and atrophy of the endometrium, therefore decreasing the amount of menstrual flow. Secondly, the levonorgestrel down regulates estrogen receptors in glandular and stromal endometrial tissues. This likely prevents further estrogen stimulation of the adenomyosis foci within the myometrium, causing them to atrophy and shrink. This may lead to decreased menstrual flow by allowing the myometrium to better contract, limiting the blood loss during menses, and also accounts for the decreased size of the uterus noted. ${ }^{41}$

Several studies have been performed to evaluate the effectiveness of the LNG-IUS as a treatment for adenomosis. In one small study of 25 women with menorrhagia associated with adenomyosis, the subjects were treated with the LNG-IUS and followed for up to 12 months. The average pictorial blood loss decreased by approximately $75 \%(211 \pm 61$ to $44 \pm 18 \mathrm{~mL})$. In addition, both uterine volume and endometrial thickness decreased significantly, while there was a significant increase in hemoglobin, serum iron and ferritin levels. ${ }^{39}$

Another study was performed on 47 women with adenomyosis. Each received a LNG-IUS and were followed for up to 36 months. At the end of 36 months 32 women were still enrolled in the study. In these women, serum hemoglobin and ferritin levels increased significantly and CA-125 values significantly decreased. In addition, uterine volume decreased from $156.85 \pm 49.79$ to $118.64 \pm 41.35 \mathrm{~mL}$ at 12 months. However, uterine volume increased from 24 to 36 months, to $139.87 \pm 29.93 \mathrm{~mL}$. At 36 months, this difference was not significantly different from the initial pretreatment volume.
Pain scores decreased significantly from $8.55 \pm 1.02$ to $1.93 \pm 0.95$ by 6 months and remained there at 24 months. Menstrual blood flow was also markedly reduced, with a reduction of $>90 \%$, and remained similar at 24 months. However, as with uterine size, the pain scores and blood flow increased again after 36 months, though they were still significantly less than the initial values. Though the exact cause for this phenomenon is unknown, it is hypothesized that it could be attributed to the decreased amount of hormone released by the LNG-IUS daily over time. ${ }^{42}$ Regardless, the LNG-IUS does appear to be an effective treatment for adenomyosis with improvement in pain and bleeding scores over two years. Further studies will need to address whether replacing the LNG-IUS after 2-3 years will keep the pain and bleeding scores from increasing again over time.

\section{The LNG-IUS as treatment for endometrial hyperplasia}

Endometrial hyperplasia is classified according to increasingly abnormal architectural and cytologic criteria as simple, complex, and atypical hyperplasia. Cytologic atypia is the most important prognostic factor with regard to progression to endometrial cancer. For nonatypical hyperplasia, there is a $1 \%-3 \%$ chance of progression to cancer, with a $72 \%$ chance of regression after expectant management. In contrast, for atypical hyperplasia there is an $8 \%-30 \%$ chance of progression to endometrial carcinoma, with only a $54 \%$ chance of spontaneous regression with expectant management. ${ }^{43}$ In addition, endometrial cancer can coexist with atypical hyperplasia in up to $25 \%$ of cases. ${ }^{44}$ Because of the high potential for progression of atypical endometrial hyperplasia to carcinoma hysterectomy is generally considered to be the standard of care unless the patient desires to retain potential fertility or there are medical contraindications to surgery. In contrast, because nonatypical hyperplasia is generally considered to be low risk for progression to cancer, many patients and providers consider hysterectomy too invasive a treatment. Though there is no consensus on the best way to treat these women, they have often been treated with oral progestins. However, because of the systemic nature of the treatment there can be significant side effects that limit compliance with treatment, and when the treatment is discontinued the hyperplasia can recur. As a result, numerous studies have been done to evaluate the LNG-IUS as an alternative therapy to hysterectomy for those with endometrial hyperplasia without atypia. One study of 12 women diagnosed with hyperplasia without atypia and eight women with atypia was performed to evaluate the 
long-term (three-year) remission rate after treatment with a LNG-IUS. Nineteen of the twenty women in this study developed a normal endometrium, with the other woman continuing to have focal atypical hyperplasia with a normal endometrial stripe at the end of 36 months. In addition, at the beginning of the study all women with atypical hyperplasia showed progesterone receptor expression in the epithelial cells. This expression declined significantly over the course of the study, marking the strong antiproliferative effect of the LNG-IUS, with its inhibition of estrogen bioactivity and suppression of the endometrium. ${ }^{45}$

A larger study was done involving long term (up to 106 months) follow up of 258 women with endometrial hyperplasia. Of these 258 women, 85 women were treated with $10 \mathrm{mg}$ oral medroxyprogesterone acetate (MPA) for 10 days per cycle for three to six months, 66 women had a LNG-IUS placed for 3-108 months, and 107 women underwent control biopsy alone with observation. After six months $100 \%$ of the LNG-IUS group responded, compared with $54 \%$ of the oral MPA group, while $50 \%$ of the observation group spontaneously regressed. After 58-106 months, 44 of the women still retained their LNG-IUS, and $100 \%$ of these women responded, compared with $63 \%$ of the women who had their LNG-IUS removed, $60 \%$ of the oral MPA group and $49 \%$ of the observation only group. There was no significant difference between these last three groups. ${ }^{46}$ Though larger studies with long term follow up need to be done for more definitive evidence, the studies so far do seem to indicate that the LNG-IUS is a superior treatment modality for endometrial hyperplasia than low dose oral progestins or observation alone.

\section{The LNG-IUS as adjunct to estrogen replacement therapy}

It is clear that in peri- and postmenopausal females who retain their uteri and desire estrogen replacement therapy secondary to climacteric side effects it is essential to provide progestin medication in order to counteract the proliferative effect of estrogen on the endometrium. The standard treatment has been to use a cyclic oral progestin preparation at the end of each cycle in combination with the estrogen. However, the oral regimen is associated with cyclic vaginal bleeding which is burdensome to some, and can also have a variety of androgenic side effects. In addition, multiple studies have shown possible links with systemic progesterone and increased cardiovascular risks in addition to increased breast cancer risks. ${ }^{47,48}$ The LNG-IUS has been studied as an alternative method of providing locally acting progestin which can accomplish the endometrial protective effects with a minimal amount of adverse side effects secondary to its significantly decreased serum concentration. One study of 40 perimenopausal women complaining of climacteric symptoms evaluated two treatment regimens: three week cyclic treatments with $2 \mathrm{mg}$ oral estradiol $\left(\mathrm{E}_{2}\right)$ valerate combined with $250 \mu \mathrm{g}$ of oral levonorgestrel for the last 10 days of each cycle versus $2 \mathrm{mg}$ of $\mathrm{E}_{2}$ valerate continuously with the LNG-IUS. After one year the subjective symptoms in both groups were improved, and none of the women had endometrial proliferation. However, in the LNG-IUS group $15 / 18$ women were amenorrheic, versus all women in the oral LNG group who continued with cyclic bleeding. ${ }^{49}$

Another study reviewed the available literature ( 19 studies with a total of 826 subjects) regarding progestin intrauterine devices in combination with estrogen, with a duration of six months to five years, and determined that none of the subjects developed endometrial hyperplasia throughout the course of the study. ${ }^{50}$

Hampton and colleagues evaluated 82 perimenopausal women treated with oral estrogen and the LNG-IUS for long term protection of the endometrium. Nonproliferative endometrium was present in $98.6 \%$ of the participants at the end of 12 months, $98.6 \%$ at 24 months, $95.5 \%$ at 36 months, $96.8 \%$ at 48 months, and $95.2 \%$ at 60 months. There were no cases of hyperplasia throughout the entire 60 month period. Amenorrhea was present in $54.4 \%$ of the women after 12 months, and $92.7 \%$ after 60 months. Overall the treatment was well tolerated, with $79.8 \%$ of the women still continuing with the estrogen and LNG-IUS after the full 60 months of the study and $92.4 \%$ of the participants rating the treatment as "good" or "very good". 51

The LNG-IUS thus appears to be a highly effective and acceptable method of providing endometrial protection for peri- and postmenopausal women who are taking estrogen replacement therapy.

\section{Patient acceptability of the LNG-IUS}

The LNG-IUS is a safe and effective device which has been shown to be useful not only as a contraceptive, but as a tool which can be used for a variety of gynecologic conditions or disorders. However, the IUS is not without its side effects. The most common side effect associated with the LNG-IUS is menstrual irregularity. In fact, nearly $25 \%$ of women discontinue using the LNG-IUS because of amenorrhea. ${ }^{1}$ Approximately $20 \%$ of LNG-IUS users will be amenorrheic by the end of 12 months, ${ }^{3}$ and $70 \%$ of users will be oligomenorrheic or amenorrheic by 24 months. ${ }^{52}$ In addition, though the systemic absorption is much smaller than with 
other progestin-containing contraceptives, there is some absorption and it can occasionally be associated with a variety of undesirable side effects such as ovarian cysts, acne, weight gain, depression and decreased libido. However, the device seems to be well tolerated overall. A three-year study which specifically set out to evaluate the long-term acceptability of the LNG-IUS followed 165 women over 36 months. The study showed a three-year continuation rate of $90.3 \%$. In total, $97 \%$ of participants reported alterations in their menstrual pattern, with 34\% reporting a decrease in the amount of bleeding, $17 \%$ had persistent spotting or intermenstrual bleeding, and $56 \%$ reported at least a temporary period of amenorrhea. $81 \%$ of the women with amenorrhea viewed it as a positive change for them. There was also a significant improvement in the amount of pain associated with menstruation, with a decrease from $60 \%$ to $29 \%$ in women reporting dysmenorrhea after 36 months. The number of women who expressed that they were very satisfied with the LNG-IUS increased steadily with the duration of the treatment, with $29 \%$ after two weeks, 56\% after two months, 69\% after six months and $77 \%$ after 36 months. ${ }^{53}$

Another study of 78 women who had the LNG-IUS inserted for menstrual disorders also evaluated patient satisfaction through questionnaires. $12 \%$ of the women had the IUS prematurely removed, with the major reason being pain and heavy bleeding. However, the majority of participants were satisfied with their results. $78 \%$ of the women reported improvement in their periods, and $84 \%$ reported improvement in menstrual discomfort. $72 \%$ of the women reported they would use the LNG-IUS again, 73\% would recommend it to their peers, and the overall satisfaction rate was $76 \%{ }^{54}$

The amount of satisfaction with the LNG-IUS, not surprisingly, appears to correlate with how well informed patients are about the possible side effects associated with it. A study that involved the evaluation of 17,914 questionnaires of current LNG-IUS users showed that $74 \%$ were very or fairly satisfied with it. User satisfaction correlated with the amount of information provided regarding different symptoms (menstrual irregularities, greasy hair/skin, pregnancy and PID) regardless of whether or not the patient actually experienced that specific symptom. In particular, the women who were warned of the possibility of amenorrhea were more satisfied than the women who were not. ${ }^{55}$

\section{Conclusion}

The levonorgestrel-releasing intrauterine system is a safe, effective and acceptable form of contraception being used by over 150 million women worldwide. It also has a multitude of noncontraceptive benefits including improvement in menorrhagia, decreased pelvic pain associated with endometriosis and adenomyosis, as well as a treatment for endometrial hyperplasia, an alternative to hysterectomy and an adjunct to estrogen replacement therapy. Overall the device is very well tolerated and patient satisfaction is quite high when the proper education regarding possible side effects has been provided. Despite all of the obvious benefits of the LNG-IUS, utilization rates remain quite low in the developed countries, and especially the United States. This is largely attributed to the negative history of the Dalkon Shield intrauterine device in the 1970s, which continues to negatively influence the opinions of both patients and health care providers. In addition, cost remains a barrier in less developed countries where demand might be high but the device is currently unaffordable in the public sector. Recently, with a concerted effort to train residents and providers in IUD and IUS use, a reversal of trends has been noted and the IUS is rapidly gaining market share in the US. This safe, acceptable and highly effective method will likely contribute significantly to the contraceptive method mix in the coming years.

\section{Disclosure}

The authors report no conflicts of interest in this work.

\section{References}

1. ESHRE Capri Workshop Group. Intrauterine devices and intrauterine systems. Hum Reprod Update. 2008;14:197-208.

2. d' Arcanges C. Worldwide use of intrauterine devices for contraception. Contraception. 2007;75:S2-S7.

3. Berlex Pharmaceuticals. Mirena ${ }^{\circledR}$ Physician Information. July 2008. Accessed on June 24, 2009. Available from: http://berlex.bayerhealthcare.com/html/products/pi/Mirena_PI.pdf.

4. Lahteenmaki P, Rauramo I, Backman T. The levonorgestrel intrauterine system in contraception. Steroids. 2000;65:693-697.

5. Sivin I. Another look at the Dalkon Shield: meta-analysis underscores its problems. Contraception. 1993;48:1-12.

6. Shelton J. Risk of clinical pelvic inflammatory disease attributable to an intrauterine device. Lancet. 2001;357(9254):443.

7. Stanback J, Shelton J. Pelvic inflammatory disease attributable to the IUD: modeling risk in West Africa. Contraception. 2008;77: 227-229.

8. Andersson K, Odlind V, Rybo G. Levonorgestrel-releasing and copper-releasing (Nova T) IUDs during five years of use: a randomized comparative trial. Contraception. 1994;49:56-72.

9. Morrison CS, Murphy L, Kwok C, Weiner DH. Identifying appropriate IUD candidates in areas with high prevalence of sexually transmitted infections. Contraception. 2007;75(3):185-192.

10. Veldhuis HM, Vos AG, Lagro-Janssen AL. Complications of the intrauterine device in nulliparous and parous women. Eur J Gen Pract. 2004;10(3):82-87.

11. Lete I, Morales P, de Pablo JL. Use of intrauterine contraceptive devices in nulliparous women: personal experience over a 12-year period. Eur $J$ Contracept Reprod Health Care. 1998;3:190-193. 
12. World Health Organization. Intrauterine devices. In: Medical Eligibility Criteria for Contraceptive Use. 3rd edition. Geneva, Switzerland: World Health Organization; 2004.

13. Ng YW, Liang S, Singh K. Effects of Mirena (levonorgestrel-releasing intrauterine system) and Ortho Gynae T380 intrauterine copper device on lipid metabolism - a randomized comparative study. Contraception. 2009;79(1):24-28.

14. Kayikcioglu F, Gunes M, Ozdegirmenci O, Haberal A. Effects of levonorgestrel-releasing intrauterine system on glucose and lipid metabolism: a 1-year follow-up study. Contraception. 2006;73: 528-531.

15. Ng YW, Liang S, Singh K. Effects of Mirena (levonorgestrel-releasing intrauterine system) and Ortho Gynae T380 intrauterine copper device on lipid metabolism - a randomized comparative study. Contraception 2009;79:24-28.

16. World Health Organization. Medical Eligibility Criteria for Contraceptive Use: 2008 Update. 2008. Accessed on May 10, 2009. Available from: http://www.who.int/reproductive-health/publications/ mec/mec_update_2008.pdf.

17. Faculty of Family Planning and Reproductive Health Care Clinical Effectiveness Unit. FFPRHC Guidance (April 2004): the levonorgestrel-releasing intrauterine system (LNG-IUS) in contraception and reproductive health. J Fam Plann Reprod Health Care. 2004; 30:99-108

18. Grimes DA, Schulz KF. Antibiotic prophylaxis for intrauterine contraceptive device insertion. Cochrane Database Syst Rev. 2001;2: CD001327.

19. Hubacher D, Reyes V, Lillo S, Zepeda A, Chen PL, Croxatto H. Pain from copper intrauterine device insertion: randomized trial of prophylactic ibuprofen. Am J Obstet Gynecol. 2006;195:1272-1277.

20. Oloto EJ, Bromham DR, Murty JA. Pain and discomfort perception at IUD insertion. Effect of short-duration, low-volume, intracervical application of 2\% lignocaine gel (Instillagel ${ }^{\mathrm{TM}}$ ) - a preliminary study Br J Fam Plann. 1997;22:177-180.

21. Sääv I, Aronsson A, Marions L, Stephansson O, Gemzell-Danielsson K. Cervical priming with sublingual misoprostol prior to insertion of an intrauterine device in nulliparous women: a randomized controlled trial. Hum Reprod. 2007;22:2647-2652.

22. Thonneau PF, Almont T. Contraceptive efficacy of intrauterine devices. Am J Obstet Gynecol. 2008;198:248-253.

23. Sivin I, Stern J, Coutinho E, et al. Prolonged intrauterine contraception: a seven-year randomized study of the levonorgestrel $20 \mathrm{mcg} / \mathrm{day}$ (LNg 20) and the Copper T380 Ag IUDS. Contraception. 1991;44 473-480.

24. Díaz J, Faúndes A, Díaz M, Marchi N. Evaluation of the clinical performance of a levonorgestrel-releasing IUD, up to seven years of use, in Campinas, Brazil. Contraception. 1993;47:169-175.

25. Rönnerdag M, Odlind V. Health effects of long-term use of the intrauterine levonorgestrel-releasing system. A follow-up study over 12 years of continuous use. Acta Obstet Gynecol Scand. 1999;78:716-721.

26. Grimes DA, Lopez LM, Manion C, Schulz KF. Cochrane systematic reviews of IUD trials: lessons learned. Contraception. 2007; 75(6 Suppl):S55-S59.

27. Pakarinen P, Toivonen J, Luukkainen T. Randomized comparison of levonorgestrel- and copper-releasing intrauterine systems immediately after abortion, with 5 years' follow-up. Contraception. 2003;68(1): 31-34.

28. Hayes JL, Cwiak C, Goedken P, Zieman M. A pilot clinical trial of ultrasound-guided postplacental insertion of a levonorgestrel intrauterine device. Contraception. 2007;76:292-296.

29. Eroğlu K, Akkuzu G, Vural G, et al. Comparison of efficacy and complications of IUD insertion in immediate postplacental/early postpartum period with interval period: 1 year follow-up. Contraception. 2006;74:376-381

30. Milsom I. The levonorgestrel-releasing intrauterine system as an alternative to hysterectomy in perimenopausal women. Contraception. 2007;75(6 Suppl):S152-S154.
31. Irvine GA, Campbell-Brown MB, Lumsden MA, Heikkilä A, Walker JJ, Cameron IT. Randomised comparative trial of the levonorgestrel intrauterine system and norethisterone for treatment of idiopathic menorrhagia. Br J Obstet Gynaecol. 1998;105(6):592-598.

32. Hurskainen R, Teperi J, Rissanen P, et al. Quality of life and cost-effectiveness of levonorgestrel-releasing intrauterine system versus hysterectomy for treatment of menorrhagia: a randomised trial. Lancet. 2001;357(9252):273-277.

33. Blumenthal P, Trussell J, Sing R, et al. Cost-effectiveness of treatments for dysfunctional uterine bleeding in women who need contraception. Contraception. 2006;74(3):249-258.

34. Lethaby A, Cooke I, Rees MC. Progesterone or progestogen-releasing intrauterine systems for heavy menstrual bleeding. Cochrane Database Syst Rev. 2005;4:CD002126.

35. Bulun SE. Endometriosis. N Engl J Med. 2009;360:268-279.

36. Petta CA, Ferriani RA, Abrao MS, et al. Randomized clinical trial of a levonorgestrel-releasing intrauterine system and a depot GnRH analogue for the treatment of chronic pelvic pain in women with endometriosis. Hum Reprod. 2005;20:1993-1998.

37. Petta CA, Ferriani RA, Abrao MS, et al. A 3-year follow-up of women with endometriosis and pelvic pain users of the levonorgestrel-releasing intrauterine system. Eur J Obstet Gynecol Reprod Biol. 2009;143:128-129.

38. Lockhat FB, Emembolu JO, Konje JC. The efficacy, side-effects and continuation rates in women with symptomatic endometriosis undergoing treatment with an intra-uterine administered progestogen (levonorgestrel): a 3 year follow-up. Hum Reprod. 2005;20:789-793.

39. Vercellini P, Frontino G, De Giorgi O, Aimi G, Zaina B, Crosignani PG. Comparison of a levonorgestrel-releasing intrauterine device versus expectant management after conservative surgery for symptomatic endometriosis: a pilot study. Fertil Steril. 2003;80:305-309.

40. Fedele L, Bianchi S, Raffaelli R, Portuese A, Dorta M. Treatment of adenomyosis-associated menorrhagia with a levonorgestrel-releasing intrauterine device. Fertil Steril. 1997;68:426-429.

41. Fong Y, Singh K. Medical treatment of a grossly enlarged adenomyotic uterus with the levonorgestrel-releasing intrauterine system. Contraception. 1999;60:173-175.

42. Cho S, Nam A, Kim H, et al. Clinical effects of the levonorgestrelreleasing intrauterine device in patients with adenomosis. Am J Obstet Gynecol. 2008;198:373.e1-e7.

43. Varma R, Soneja H, Bhatia K, et al. The effectiveness of a levonorgestrel-releasing intrauterine system (LNG-IUS) in the treatment of endometrial hyperplasia - a long-term follow-up study. Eur J Obstet Gynecol Reprod Biol. 2008;139:169-175.

44. Clark TJ, Neelakantan D, Gupta JK. The management of endometrial hyperplasia: an evaluation of current practice. Eur J Obstet Gynecol Reprod Biol. 2006;125:259-264.

45. Wildemeersch D, Janssens D, Pylyser K, et al. Management of patients with non-atypical and atypical endometrial hyperplasia with a levonorgestrel-releasing intrauterine system: long-term follow-up. Maturitas. 2007;57:210-213.

46. Ørbo A, Arnes M, Hancke C, Vereide AB, Pettersen I, Larsen K. Treatment results of endometrial hyperplasia after prospective D-score classification: a follow-up study comparing effect of LNG-IUD and oral progestins versus observation only. Gynecol Oncol. 2008;111:68-73.

47. Rossouw JE, Anderson GL, Prentice RL, et al. Risks and benefits of estrogen plus progestin in healthy postmenopausal women: principal results from the Women's Health Initiative randomized controlled trial. JAMA. 2002;288:321-333.

48. Hulley S, Grady D, Bush T, et al. Randomized trial of estrogen plus progestin for secondary prevention of coronary heart disease in postmenopausal women. Heart and Estrogen/progestin Replacement Study (HERS) Research Group. JAMA. 1998;280(7):605-613.

49. Andersson K, Mattsson LA, Rybo G, Stadberg E. Intrauterine release of levonorgestrel - a new way of adding progestogen in hormone replacement therapy. Obstet Gynecol. 1992;79:963-967.

50. Riphagen FE. Intrauterine application of progestins in hormone replacement therapy: a review. Climacteric. 2000;3:199-211. 
51. Hampton NR, Rees MC, Lowe DG, Rauramo I, Barlow D, Guillebaud J. Levonorgestrel intrauterine system (LNG-IUS) with conjugated oral equine estrogen: a successful regimen for HRT in perimenopausal women. Hum Reprod. 2005;20:2653-2660.

52. ACOG Committee on Practice Bulletins-Gynecology. ACOG practice bulletin. Clinical management guidelines for obstetrician-gynecologists. Number 59, January 2005. Intrauterine device. Obstet Gynecol. 2005;105:223-232.

53. Baldaszti E, Wimmer-Puchinger B, Löschke K. Acceptability of the long-term contraceptive levonorgestrel-releasing intrauterine system (Mirena): a 3-year follow-up study. Contraception. 2003 Feb; 67(2):87-91.
54. Radesic B, Sharma A. Levonorgestrel-releasing intrauterine system for treating menstrual disorders: a patient satisfaction questionnaire. Aust N Z J Obstet Gynaecol. 2004;44:247-251.

55. Backman T, Huhtala S, Luoto R, Tuominen J, Rauramo I, Koskenvuo M. Advance information improves user satisfaction with the levonorgestrel intrauterine system. Obstet Gynecol. 2002;99:608-613. 
Appendix A Checklist for sexually transmitted infection (STI) risk assessment of intrauterine device (IUD) candidates ${ }^{8}$

\section{Checklist for STI Risk Assessment of IUD Candidates}

Name:

Date:

Please circle the appropriate answers below:

$\begin{array}{cc}\frac{\text { Yes }}{1} & \frac{\text { No }}{1} \\ 1 & 0 \\ 1 & 0 \\ 1 & 0\end{array}$

4. Is her school education less than secondary level? ${ }^{\dagger}$

5. How many different sexual partners has she had during the last 3 months? Check $A$ if none, $B$ if
one, $C$ if more than one.

If $B$ or $C$, then ask her how often she used a condom when she had sex during the last 3 months (never, some or always)?

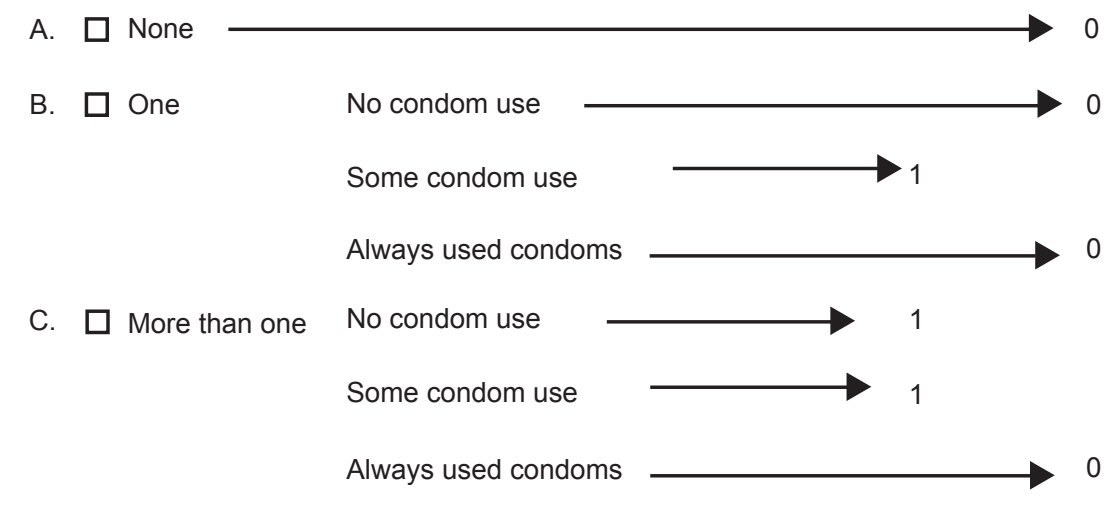

Add up the circled scores.

Total Score:

\section{Scoring}

\section{Recommended Action}

Counsel/refer for an IUD insertion without any reservations

Consider presumptive treatment for chlamydia/gonorrhea (if available) or counsel/refer to use another contraceptive method

${ }^{\top}$ The level may change from less than secondary level to a higher educational level if almost all women $(>90 \%)$ have at least some secondary 
Appendix B WHO risk categories for eligibility for use of an intrauterine device ${ }^{12}$

\begin{tabular}{|c|c|c|c|}
\hline Risk category & Description of category & With clinical judgment & Without clinical judgment \\
\hline I & $\begin{array}{l}\text { A condition for which there is } \\
\text { no restriction for the use of } \\
\text { the contraceptive method }\end{array}$ & $\begin{array}{l}\text { Use the method in any } \\
\text { circumstances }\end{array}$ & Use the method \\
\hline 2 & $\begin{array}{l}\text { A condition where the } \\
\text { advantages of using the } \\
\text { method generally outweigh } \\
\text { the theoretical or proven risks }\end{array}$ & Generally use the method & Use the method \\
\hline 3 & $\begin{array}{l}\text { A condition where the } \\
\text { theoretical or proven } \\
\text { risks usually outweigh the } \\
\text { advantages of using the } \\
\text { method }\end{array}$ & $\begin{array}{l}\text { Use of the method not } \\
\text { usually recommended unless } \\
\text { other more appropriate } \\
\text { methods are not available or } \\
\text { not acceptable }\end{array}$ & Do not use the method \\
\hline 4 & $\begin{array}{l}\text { A condition which represents } \\
\text { an unacceptable health risk } \\
\text { if the contraceptive method } \\
\text { is used }\end{array}$ & Method not to be used & Do not use the method \\
\hline
\end{tabular}

Notes: "Clinical Judgement" means that a trained health care provider or the clinical resources to perform clinical tests and/or examinations are present.

\section{Publish your work in this journal}

Therapeutics and Clinical Risk Management is an international, peerreviewed journal of clinical therapeutics and risk management, focusing on concise rapid reporting of clinical studies in all therapeutic areas, outcomes, safety, and programs for the effective, safe, and sustained use of medicines. This journal is indexed on PubMed Central, CAS,
EMBase, Scopus and the Elsevier Bibliographic databases. The manuscript management system is completely online and includes a very quick and fair peer-review system, which is all easy to use. Visit http://www.dovepress.com/testimonials.php to read real quotes from published authors.

Submit your manuscript here: http://www.dovepress.com/therapeutics-and-clinical-risk-management-journal 